\title{
ANATOMÍA E HISTOQUÍMICA DE LA SEMILLA DEL CACAO (Theobroma cacao L.) CRIOLLO MEXICANO
}

\author{
ANATOMY AND HISTOCHEMISTRY OF THE MEXICAN CACAO \\ (Theobroma cacao L.) SEED
}

\begin{abstract}
Ma. Alma Rangel-Fajardo ${ }^{1}$, Hilda A. Zavaleta-Mancera ${ }^{2 *}$, Leobigildo Córdova-Téllez ${ }^{1}$, Alejandro P. López-Andrade ${ }^{3}$, Adriana Delgado-Alvarado ${ }^{4}$, Ignacio Vidales-Fernández ${ }^{5}$ y Ángel Villegas-Monter ${ }^{1}$
\end{abstract}

${ }^{1}$ Postgrado en Recursos Genéticos y Productividad y ${ }^{2}$ Postgrado en Botánica, Colegio de Postgraduados-Campus Montecillo. Km. 36.5 Carretera México-Texcoco. 56230, Montecillo, Texcoco, Edo de México. ${ }^{3}$ Campo Experimental Huimanguillo, Instituto Nacional de Investigaciones Forestales, Agrícolas y Pecuarias. Km 1. Carretera Huimanguillo-Cárdenas. 86400, Huimanguillo, Tabasco, México. ${ }^{4}$ Postgrado en Estrategias para el Desarrollo Agrícola Regional, Colegio de Postgraduados-Campus Puebla. Km. 125.5 Carretera México-Puebla. 72760, Santiago Momoxpan, San Pedro Cholula, Puebla. ${ }^{5}$ Campo Experimental Uruapan, Instituto Nacional de Investigaciones Forestales, Agrícolas y Pecuarias. Av. Latinoamericana 1101, Col. Revolución. 60150, Uruapan, Michoacán, México.

*Autor para correspondencia (arazavaleta@yahoo.com)

\section{RESUMEN}

El presente estudio contribuye al conocimiento del ovulo, saco embrionario, anatomía e histoquímica de la semilla del cacao (Theobroma cacao L.) mexicano criollo 'Carmelo' y la relación de tales características con la recalcitrancia. Muestras de flores en antesis y semillas en desarrollo se procesaron para observaciones anatómica (teñidos con safranina y verde fijo) e histoquímicas de lípidos, proteínas, almidón y taninos. Se encontró que el óvulo es anátropo, crasinucelado y bitégmico, con endospermo nuclear, caracteres que han sido asociados con la recalcitrancia en $\mathbf{4 5}$ familias de dicotiledóneas. El tegumento interno (ti) forma un endostomo y exostomo no alineados. El saco embrionario presenta tres antípodas, dos sinérgidas, una ovocélula y una célula central binucleada. Después de la fecundación se forman ramas postcalazales que penetran el tegumento externo. El tegumento interno en antesis (dos a tres estratos) se engrosa al inicio del desarrollo (ocho a 10 estratos en semillas de $1 \mathrm{~cm}$ ), pero luego se colapsa. El tegumento externo (tres a cuatro estratos en antesis) es multiplicativo; la mesotesta se divide ( 25 a 27 estratos) y luego se colapsa parcialmente. Los sacos de mucílago de la testa se originan de las células debajo de la exotesta. La pulpa del fruto se mantiene adherida a la exotesta, carácter asociado con la recalcitrancia de la semilla. El embrión presenta un crecimiento retardado, el estado globular $(40 \mu \mathrm{m})$ está presente en semillas de $1 \mathrm{~cm}$ de largo. Los cotiledones jóvenes son foliosos y rectos (semillas de 1.5 $\mathrm{cm}$ ), hacia la madurez se engrosan y pliegan sobre el eje embrionario. El endospermo se reduce a dos estratos en la madurez. Los cotiledones inician la acumulación de almidón y proteína en semillas de $1.5 \mathrm{~cm}$ (Etapa VI: frutos de 21.0 a $23.9 \mathrm{~cm}$ ); los lípidos se acumulan cuando los cotiledones se pliegan, Etapa VII (frutos de 21.0 a $23.9 \mathrm{~cm}$ ); y los taninos se acumulan en idioblastos hacia el final del desarrollo.

Palabras clave: Theobroma cacao, Sterculiaceae, anatomía de semilla, histoquímica.

\section{SUMMARY}

The present research contributes knowledge of the embryo sac, seed anatomy and histochemistry of the Mexican cacao (Theobroma cacao L.) cv. 'Carmelo', and the relationship of these traits to seed recalcitrance. Flowers in anthesis and developing seeds were processed for anatomical (safranin and fast green) and histochemical evaluations of starch, lipids, proteins and tannins. It was found that the ovule is anatropous, crassinucellate and bitegmic with nuclear endosperm, characteristics significantly associated with recalcitrance of 45 dicotyledon families. The incipient growth of the inner tegument forms an endostome and exostome out of alignment. The embryo sac is formed by three antipodal cells, two synergids, one egg cell and one binucleated central cell. The inner integument (two to three layers) becomes thicker at the beginning of development (eight to 10 layers in $1 \mathrm{~cm}$ seeds), but afterwards it collapses. The outer integument (three to four layers at anthesis) is multiplicative; the mesotest divides (25 to 27 layers), and then it partially collapses. Mucilage sacs of testa originate from hypodermal cells of the exotesta. The fruit flesh is maintained attached to the testa, a trait associated to recalcitrance. The embryo shows a late growth, and the globular stage $(40 \mu \mathrm{m})$ is present in seeds of $1 \mathrm{~cm}$. Young cotyledons are straight and foliar $(1.5 \mathrm{~cm}$ seeds), but at maturity they are thick and folded over the embryo axis. The endosperm is reduced to two layers at maturity. Cotyledons start to accumulate starch and proteins in seeds of $1.5 \mathrm{~cm}$ (Stage VI: fruits of 21.0 to $23.9 \mathrm{~cm}$ ); lipids start when cotyledons folds (Stage VII: fruits of 21.0 to $23.9 \mathrm{~cm}$ ), and tannins accumulate in idioblasts at the end of seed development.

Index words: Theobroma cacao, Sterculiaceae, seed anatomy, histochemistry.

\section{INTRODUCCIÓN}

El cacao (Theobroma cacao L.) es una especie tropical de la familia Sterculiaceae que se distribuye en forma natural en los estratos medios de las selvas cálidas húmedas del hemisferio occidental, entre $18^{\circ} \mathrm{LN}$ (en los Estados de Veracruz, Tabasco y Chiapas, México) y $15^{\circ}$ LS (Brasil y Bolivia), y desde el nivel del mar hasta $1000 \mathrm{~m}$ (Cuatrecasas, 1964). El cacao fue cultivado por los mayas, cuya semilla tostada y molida usaron para elaborar bebidas de chocolate y su consumo estuvo asociado con riqueza y poder. Los mayas establecieron las primeras plantaciones cacaoteras en Centroamérica. En el mundo se reconocen tres tipos de cacao, con base en la diversidad morfológica observada en Centro y Sudamérica. Se ha propuesto la evolución de dos grupos morfo-geográficos reconocidos como subespecies: T. cacao ssp. Cacao (Criollo) y T. cacao ssp. Sphaerocapum (Forastero) (Mendoza-López et al., 2011). Un tercer grupo originado de cruzas naturales del Criollo y Forastero 
es llamado Trinitario, por haberse generado en Trinidad y Tobago (Cuatrecasas, 1964). El cacao Criollo es el de mayor calidad por su fino sabor y aroma, aunque el Forastero de sabor amargo es el más cultivado y comercializado por su tolerancia a enfermedades (Mendoza-López et al., 2011).

No todas las semillas responden al almacenamiento de la misma manera. Las semillas ortodoxas pueden secarse y almacenarse ex situ sin sufrir daño (Roberts, 1973). El cacao pertenecen al grupo de semillas recalcitrantes, las cuales presentan la característica de no poder secarse sin sufrir daño pues su viabilidad se reduce con la desecación y al llegar a un "contenido de humedad crítico" la viabilidad se reduce a cero (Roberts, 1973). A diferencia de las semillas ortodoxas, las recalcitrantes contienen altos contenidos de humedad a la madurez y aunque se almacenen hidratadas no pueden ser preservadas porque metabólicamente sufren cambios similares a la germinación y finalmente mueren por estrés oxidativo (Pammenter et al., 1994). El contenido de humedad crítico varía entre especies desde $23 \%$ en cacao a 61 \% en Avicenia marina (Hong y Ellis 1996) y aún entre genotipos; por ejemplo, el criollo 'Carmelo' es menos tolerante que los genotipos 'EET 48' (Forastero) y 'UF 667' (Trinitario) (Rangel et al., 2011). Estas semillas son deficientes en reducir su sistema enzimático durante la desecación (Bewley, 1995; Roberts, 1973).

La alta proporción de rafinosa:sacarosa $(0.22$ a 0.28$)$ en genotipos de cacao se relaciona directamente con una mayor tolerancia a la desecación (Rangel-Fajardo et al., 2011), y esta condición dificulta su conservación ex situ. Poco se conoce sobre la relación entre la estructura del óvulo y semilla con la recalcitrancia. Teichman y van Wyk (1994) revisaron los aspectos estructurales y tendencias evolutivas de semillas recalcitrantes en 45 familias de dicotiledóneas, pero no incluyeron géneros de la familia Sterculiaceae; estos autores proponen que el tamaño de la semilla, tipo de reserva (exalbuminosa), y caracteres en el óvulo (tipo de calaza, número de tegumentos y tipo de nucela) están significativamente asociados con la recalcitrancia en semillas. La estructura de las semillas recalcitrantes tiene una función importante en la sensibilidad a la desecación; por ejemplo, las cubiertas gruesas y duras actúan como barreras para prevenir la deshidratación y en ocasiones evitan la imbibición, y por tanto están directamente relacionadas con el nivel de desecación de la semilla (Moreno et al., 2006; Farnsworth, 2000; Chacón y Bustamente, 2001).

Las características anatómicas de óvulos y semillas de los géneros de la familia Sterculiaceae se han estudiado poco, y entre las estudiadas están Sterculia striata (González y Cristóbal, 2006), Brachichiton (Guymer, 1988), Sterculia foetica y S. colorata (González y Cristóbal, 2006). Roth y Lindford
(1971) ilustran mediante dibujos el desarrollo del fruto y de la testa de T. cacao proveniente de la Isla de Grenada y Maracay, pero no especifican el genotipo usado; sus observaciones las hicieron en cortes a mano de material preservado en agua y glicerina, y no presentan resultados de óvulo y saco embrionario, ni del desarrollo embrionario.

El conocimiento actual de la semilla de cacao está basado en los tipos Forastero y Trinitario, mientras que la anatomía seminal del cacao Criollo mexicano no se conoce. Estudios relacionados con la histoquímica y embriología en estas especies son pocos a pesar de ser relevantes, sobre todo en las que presentan alogamia, pues tales conocimientos ayudarían a una mejor conservación ex situ, propagación vegetativa y propagación in situ. Por tanto, el objetivo del presente trabajo fue contribuir al conocimiento del óvulo, saco embrionario, desarrollo e histoquímica del embrión y endospermo y tejidos maternos (nucela y tegumentos) del cacao criollo Mexicano 'Carmelo', así como para relacionar los caracteres estructurales de la semilla con las tendencias evolutivas de las semillas recalcitrantes.

\section{MATERIALES Y MÉTODOS}

El muestreo se hizo completamente al azar en cinco árboles de genotipos criollos 'Carmelo' de cacao de la colección viva del Instituto Nacional de Investigaciones Forestales, Agrícolas y Pecuarias, ubicada en el predio "El Danubio" a $18^{\circ} 14^{\prime} 24^{\prime \prime} \mathrm{LN}$ y $93^{\circ} 12^{\prime} 00^{\prime \prime} \mathrm{LO}$, a $10 \mathrm{msnm}$, en Comalcalco, Tabasco, México. Se colectaron 20 flores en antesis y 40 frutos en diferentes etapas de desarrollo, y se agruparon en ocho etapas de acuerdo con la longitud del fruto: Etapa I: 3.0 a 5.9 cm; Etapa II: 6.0 a 8.9 cm; Etapa III: 9.0 a 11.9 cm; Etapa IV: 12.0 a $14.9 \mathrm{~cm}$; Etapa V: 15.00 a $17.9 \mathrm{~cm}$; Etapa VI: 18.0 a 20.9 cm; Etapa VII: 21.0 a 23.9 cm y Etapa VIII: > $26.4 \pm 2.3 \mathrm{~cm}$, en madurez de corte.

En los frutos se midió $(\mathrm{cm})$ largo, ancho y espesor de 10 semillas y la longitud del embrión, en cada etapa. Para el estudio de desarrollo se fijó en FAA un promedio de 20 flores y 20 semillas por cada etapa, y las muestras se procesaron para su inclusión en parafina (Ruzin, 1999). Cortes seriados $(10 \mu \mathrm{m})$ se tiñeron con safranina salina $(0.05 \%$ safranina, 2 $\% \mathrm{p} / \mathrm{v} \mathrm{NaCl}$ en etanol $50 \%$ ) y verde fijo FCF ( $0.12 \%$ verde FCF en etanol $95 \%$ ), como indicaron Zavaleta y Engleman (1994).

Para el estudio histoquímico se usó un promedio de 20 semillas por etapa, y las muestras se conservaron a $-10^{\circ} \mathrm{C}$. De éstas se obtuvieron cortes transversales $(40 \mu \mathrm{m})$ con un microtomo de mano (R. Jung Ag Heidelberg 20175®; Germany) en los que se hicieron tinciones específicas: para lípidos con rojo "O" de aceite $(0.5 \%$ p/v rojo "O" de aceite, $25 \%$ v/v de 1-butanol, $75 \%$ v/v etilenglicol) según 
Zavaleta-Mancera y Engleman (1991); para almidón con $0.5 \% \mathrm{I}_{2} \mathrm{KI}$; para lignina con fluoroglucinol $(2 \%)$ y $\mathrm{HCl}$ (50\%); para polisacáridos insolubles (PAS) con ácido periódico y reactivo de Schiff (Jensen, 1962; modificada por Zavaleta-Mancera y Engleman, 1991); y para proteína con azul negro de naftol y taninos (leucoantocianinas y catequinas) con vainillina y $\mathrm{HCl}$ (Ruzin, 1999). Los cortes se observaron en un microscopio óptico compuesto Axioskop 2 Plus ${ }^{\circledR}$ (Zeiss; Germany) y se fotografiaron con una cámara AxioCam Mrc 5® (Zeiss; Germany).

\section{RESULTADOS}

\section{Estructura del óvulo y semilla en desarrollo}

En antesis el ovario es súpero pentacarpelar y sincárpico, que en corte transversal presenta cinco lóculos con dos hileras de óvulos por lóculo (Figura 1A). En corte longitudinal muestra de cinco a seis óvulos por hilera con placentación axial. Del total de óvulos observados en antesis, 50 \% se desarrolló en semilla, uno de cada par en la hilera por lóculo. En antesis los óvulos son maduros, bitégmicos, cracinucelados, y anátropos. El tegumento externo, de tres a cuatro estratos, crece más que el interno de dos a tres células, el cual sólo cubre 3/4 de la longitud de la nucela, y el micrópilo queda formado por un exostomo.

En antesis la vascularización del óvulo es incipiente, el procámbium no presenta desarrollo de elementos traqueales, sube por el funículo y rafe hasta llegar a la calaza (unión de los tegumentos con la nucela), la cual se distingue en la base de la nucela por sus células pequeñas, isodiamétricas con núcleos densos. La nucela es recta y crasinucelada, el saco embrionario se ubica separado de la epidermis por seis estratos parietales. Después de la fecundación, Etapa I, el tejido vascular desarrolla un conjunto de haces postcalazales que penetran el tegumento externo. La presencia de una nucela recta, un micrópilo o exostomo cercano al hilo, una calaza opuesta al micrópilo y una extensa rafe, son características típicas de un óvulo anátropo (Figura 1C).

El estudio de cortes seriados reveló a un saco embrionario formado por siete células y ocho núcleos; tres sinérgidas, dos antípodas, una ovocélula y dos núcleos centrales (Figura 1B-C). El tegumento externo es multiplicativo y al madurar constituye la principal cubierta protectora de la semilla. El tegumento interno inicia (antesis) con tres a cuatro estratos de células parenquimáticas isodiamétricas de paredes delgadas sin taninos, la rafe termina en la calaza, pero luego (Etapa II) se extiende en brazos postcalazales que recorren el tegumento externo. La epidermis interna del tegumento externo (endotesta) se divide periclinalmente y forma hileras anticlinales de células pequeñas; las células de la mesotesta se dividen y alargan principalmente en la región interna a los haces postcalazales (20 estratos) (Etapa II).

Cuando la semilla alcanza $1 \mathrm{~cm}$ de largo (Etapa V, frutos $15.0 \mathrm{a} 17.9 \mathrm{~cm}$ ), varias células debajo de la exotesta se alargan anticlinalmente y forman vacuolas grandes (Figura 2A). Cuando la semilla mide $1.5 \mathrm{~cm}$ (Etapa VI) el estrato subepidérmico continúa su alargamiento anticlinal, y las células forman vacuolas grandes con mucílago (50 a $60 \mu \mathrm{m}$ ) (Figura 2B). En semillas de $2.0 \mathrm{~cm}$ de largo (Etapa VII; frutos 21.0 a $23 \mathrm{~cm}$ ) las células de mucílago se hinchan y rompen para formar cavidades grandes con mucílago, mientras que la exotesta se mantiene uniestratificada e intacta (Figura 2C). Durante todo el desarrollo el parénquima del pericarpio se mantiene adherido a la exotesta, se alarga anticlinalmente y se mantiene siempre unido a la semilla (Figura 2D). En la semilla madura (Etapa VIII; frutos $>25$ $\mathrm{cm})$ la mesotesta se colapsa parcialmente y las cavidades con mucílago se alargan más (100 a $150 \mu \mathrm{m}$ ); la exotesta no cambia pero el tegumento interno se colapsa completamente (Figura 2D).

El desarrollo del embrión es lento con respecto al de la cubierta seminal y del fruto. Después de la doble fecundación (Etapa I: frutos 3.0 a $5.9 \mathrm{~cm}$ ) el embrión se detiene en el estado globular hasta la Etapa III (frutos 9.0 a 11.9) (Figura $1 \mathrm{G})$. En la Etapa IV (12.0 a $14.9 \mathrm{~cm}$ ) el embrión es pequeño y acorazonado de 0.6 a $0.7 \mathrm{~mm}$. En la Etapa V (15.0 a -17.9 $\mathrm{cm}$ ) la semilla mide $10 \mathrm{~mm}$, pero el embrión se mantiene pequeño ( 1.5 a $2.0 \mathrm{~mm}$ ) con un eje embrionario cilíndrico $\mathrm{y}$ dos cotiledones foliosos aplanados dorsiventralmente ( $\mathrm{Fi}$ gura 3C). En la Etapa VI ( 8.0 a $20.9 \mathrm{~cm})$ el embrión es de 4 a $5 \mathrm{~mm}$ de largo (Figura 3D). En frutos 21.0 a $23.9 \mathrm{~cm}$ (Etapa VII), el embrión es de $20 \mathrm{~mm}$ de largo, pero los cotiledones se mantienen delgados y rodeados de endospermo (Figura $3 \mathrm{E})$.

A partir de este estadio los cotiledones de color blanquecino crecen, se pliegan alrededor del eje embrionario y engrosan para ocupar de 85 a $90 \%$ del volumen de la semilla (Figura 3F). En frutos de la Etapa VIII (frutos maduros) el embrión presenta idioblastos con taninos aislados y dispersos en el parénquima cotiledonar (Figura 3D). El eje embrionario cilíndrico siempre se ubica orientado hacia el micrópilo (Figura 3F). El desarrollo del endospermo del cacao 'Carmelo' es de tipo nuclear, como reportaron Chopra y Sachar (1963); inicia con divisiones nucleares, luego forma paredes celulares en la región micropilar pero se mantiene cenobial en la calaza hasta que el embrión alcanza su longitud total. En la semilla madura el endospermo queda reducido a dos estratos de células parenquimatosas los cuales forman una delgada membrana blanquecina (dos a tres estratos celulares) que cubre a los cotiledones desde la Etapa VII (Figura 3G-H). La nucela es absorbida 

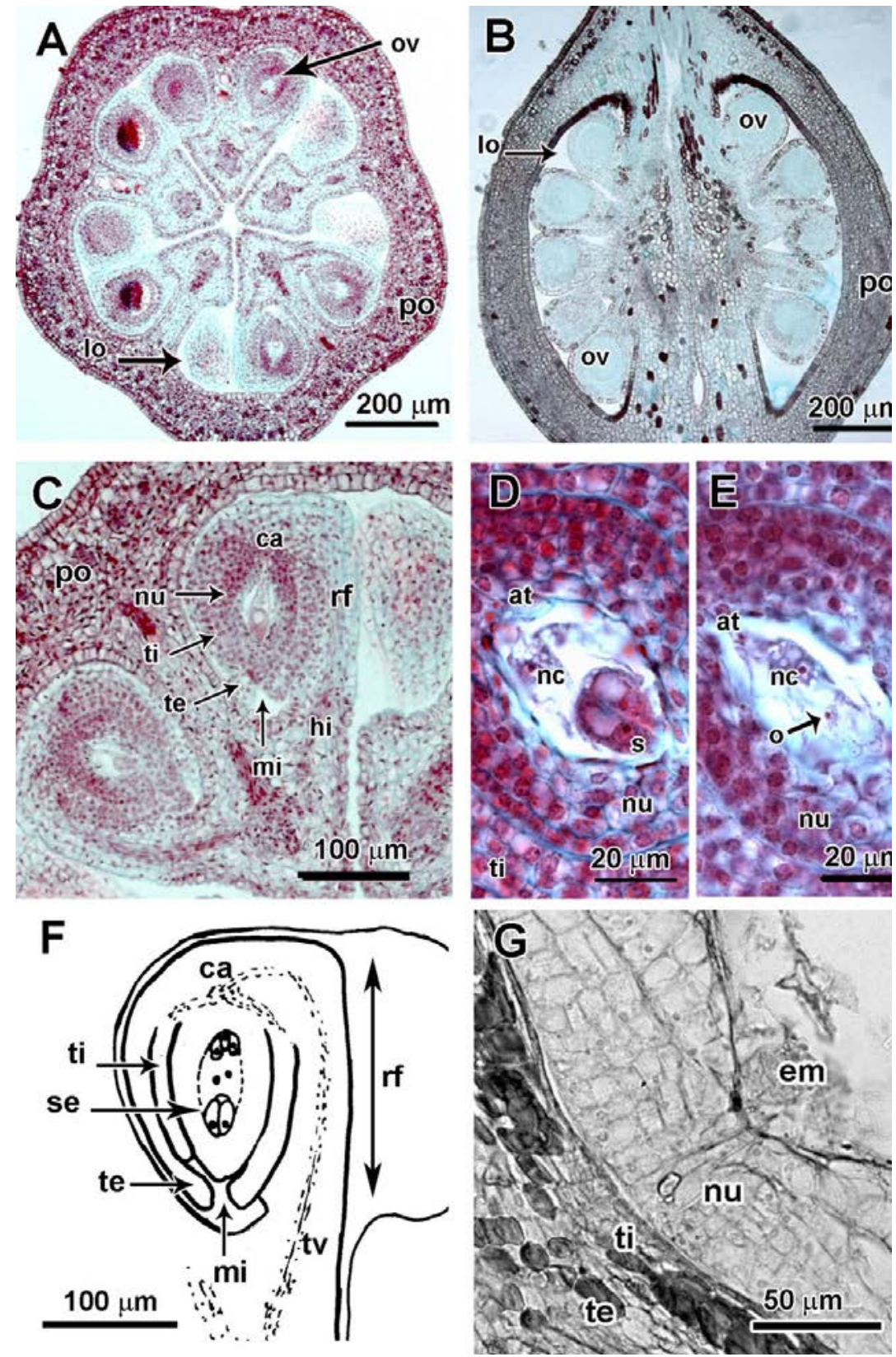

Figura 1. Óvulo y saco embrionario de Theobroma cacao L. criollo en antesis. A) Corte transversal. B) Corte longitudinal del ovario. C) Corte mediano del óvulo anátropo. D y E) Cortes seriados de un saco embrionario que muestran siete células con ocho núcleos; dos sinérgidas, dos núcleos centrales, núcleo de la ovocélula y tres antípodas. F) Dibujo del óvulo anátropo que muestra el crecimiento incipiente del tegumento interno (ti); nucela recta, micrópilo opuesto a la calaza y cercano al hilo. G) Embrión en estado globular de semillas de las Etapas I y II y III (frutos de 3.0 a $11.9 \mathrm{~cm}$ ). po = pared del ovario; lo = lóculo; ov = óvulo; $\mathrm{t} i=$ tegumento interno; te $=$ tegumento externo; $\mathrm{ca}=$ calaza; $\mathrm{m}=$ micrópilo; $\mathrm{r}=$ rafe; $\mathrm{s}=$ sinérgidas; $\mathrm{nc}=$ núcleos centrales; un $=$ nucela.

completamente durante el desarrollo y está ausente en la madurez. En la semilla pre-madura VII y madura VIII los haces postcalazales se observan como cordones blanquecinos, que contrastan con el color de la testa (Figura $3 \mathrm{H}$ ). La semilla madura es ovoide de $2.4 \pm 0.12 \mathrm{~cm}$ de longitud y 1.4 $\pm 0.08 \mathrm{~cm}$ y $0.85 \pm 0.07 \mathrm{~cm}$ de ancho y espesor. Los cotile- dones se encuentran fuertemente plegados y rodeando por completo al eje embrionario (Figura $3 \mathrm{H}$ ). El eje embrionario es cilíndrico de color blanquecino, de 0.7 a $0.8 . \mathrm{cm}$ de longitud. Los cotiledones de los genotipos criollos son de color beige \#F5F5DC, de acuerdo con el código HTLM (http://html-color-codes.info/\#Html_Color_Chart). 

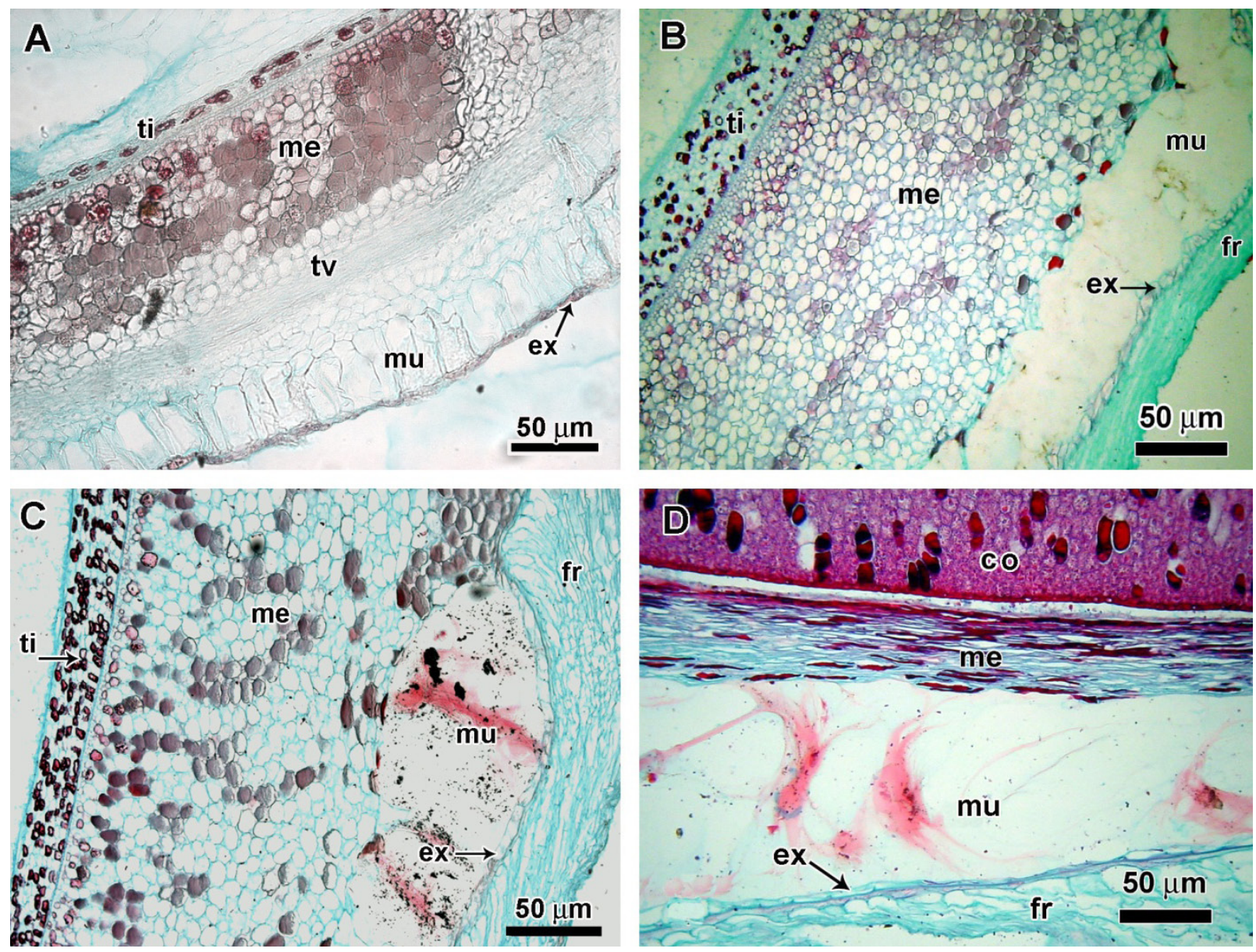

Figura 2. Desarrollo de la cubierta seminal de Theobroma cacao L. criollo. A) Semilla de frutos de la Etapa V (frutos de 15.0 a $17.9 \mathrm{~cm}$ ). B) Etapa VI (frutos de 18.0 a $20.9 \mathrm{~cm}$, semillas de $1.5 \mathrm{~cm}$ ). C) Etapa VII (frutos de 21.0 a $23.9 \mathrm{~cm}$ ). D) Etapa VIII (frutos maduros $>25 \mathrm{~cm}$ ). $\mathrm{Ti}=$ tegumento interno; $\mathrm{me}=$ mesotesta; $\mathrm{ex}=$ exotesta; $\mathrm{c}=$ cotiledón; $\mathrm{mu}=$ mucílago; $\mathrm{fr}=$ pared del fruto.

\section{Histoquímica}

Las principales substancias de reserva cotiledonar son lípidos, almidón y proteínas. Almidón y proteínas son los primeros en acumularse en semillas de $1.5 \mathrm{~cm}$ (Etapa VI; frutos de $21.0 \mathrm{a} 23.9 \mathrm{~cm}$ ) (Figura 4A). Las proteínas se acumulan en forma de gránulos amorfos (Figura 4B). La acumulación de lípidos inicia cuando los cotiledones empiezan a plegarse, en semillas de la Etapa VII (frutos 21.0 a 23.9), en forma de pequeñas gotas de aceite (esferosomas) que luego aumentan en tamaño y número para alcanzar su máxima acumulación en la madurez de corte (Etapa VIII) (Figura 4C). Los taninos se ubican principalmente en la testa de la semilla madura, y los cotiledones maduros muestran idioblastos dispersos con taninos condensados (Figura 4D).

\section{DISCUSIÓN}

En el presente estudio se describe por primera vez el saco embrionario de Theobroma cacao, el cual está formado por siete células y ocho núcleos (dos sinérgidas, una ovocélula, tres antípodas y una célula central binucleada), arreglo característico de un tipo Polygonum, cuyo origen monospórico requiere ser revisado (Johri, 1984). El óvulo del cacao criollo ‘Carmelo' se observó bitégmico y crasinucelado, como reportaron Corner (1976) para la familia Sterculiaceae. En antesis el óvulo presenta una calaza limitada, y después de la doble fecundación forma brazos postcalazales que penetran el tegumento externo, desarrollo que no se había descrito previamente.

El tegumento interno crece menos que el externo y se forma un endostoma alineado al exostoma; este crecimiento diferenciado es común en la familia Sterculiaceae (Byttneria, Guazuma y Helicteres) (Corner, 1976); un caso extremo es el de Sterculia striata cuya nucela y endostomo se observan en posición hemianátropa, mientras que el tegumento externo continúa creciendo $180^{\circ}$ y forma un exostomo cercano al 

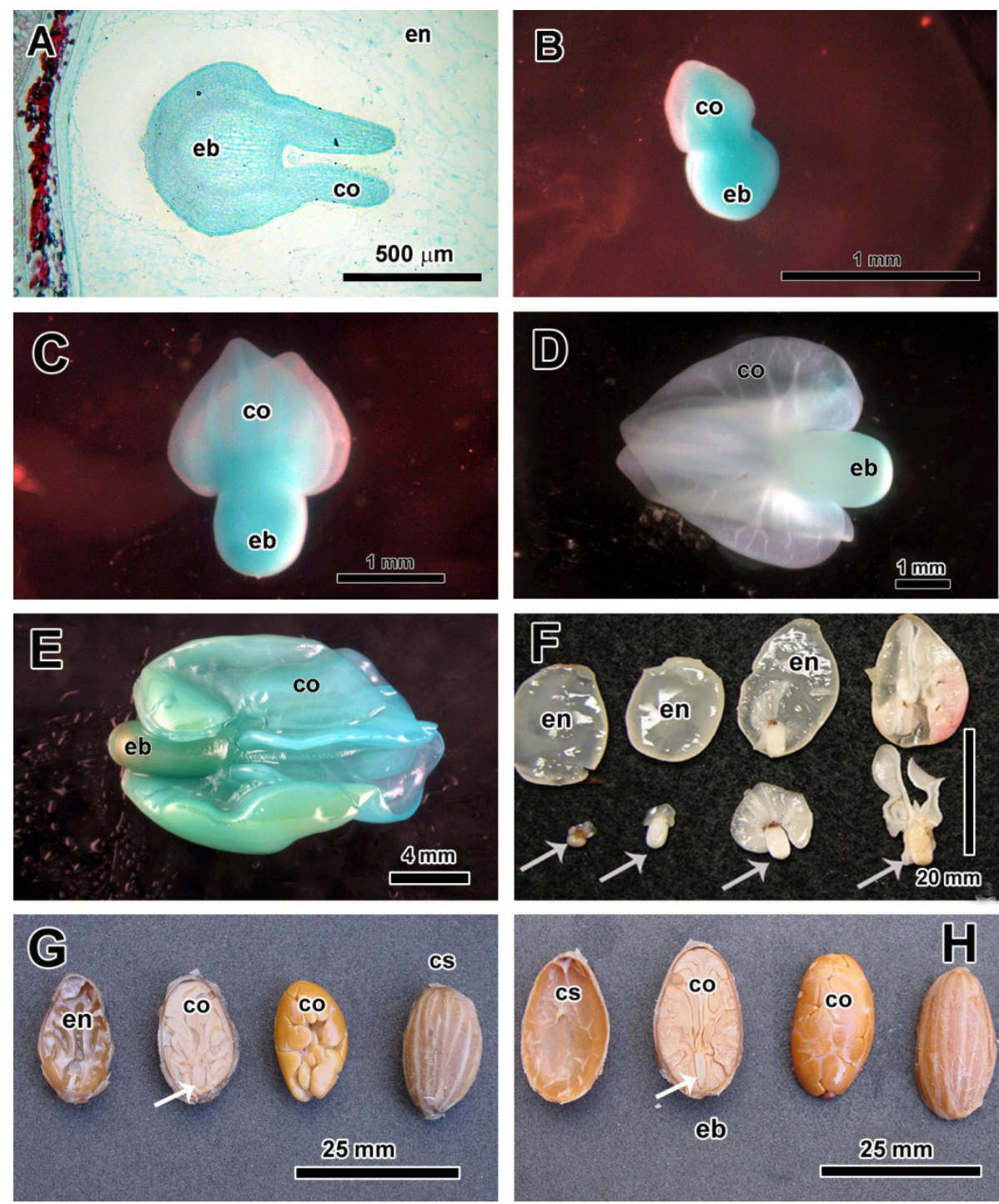

Figura 3. Desarrollo del embrión de Theobroma cacao L. criollo mexicano. A y B) Etapa IV (embriones de 0.5 a $1.0 \mathrm{~mm}$ en semillas de $1 \mathrm{~cm}$ ). C y D) Etapa V (embriones de 1.6 a $4.2 \mathrm{~mm}$ ). E) Etapa VI (embriones de 12 a $14 \mathrm{~mm}$ ). F) Secuencia del crecimiento del embrión (flechas) y reducción del endospermo (en). G) Etapa VII, semilla con restos de endospermo adherido a la parte interna de la testa (embrión de $17 \mathrm{a} 20 \mathrm{~mm}$ ). H) Etapa VIII, semilla madura con endospermo casi ausente (embriones de 24a $26 \mathrm{~mm}$ ). El color verdoso del embrión en B, C y D es resultado del colorante verde fijo agregado a la solución preservativa. F, G y H muestran el color natural del embrión. eb = eje embrionario; $c 0$ = cotiledones; en = endospermo; $c s=$ cubierta seminal.

hilo, como en óvulos hemianátropos (González y Cristóbal, 2006); el embrión de Sterculia fue descrito como invertido debido a que el exostomo se observó desalineado de la radícula.

La testa del cacao criollo es multiplicativa como la mayoría de los miembros de la familia, y los sacos de mucílago en la mesotesta se presentan también en Sterculia, Firmiana, Guazuma, Scaphium (Roth y Lindorf, 1971; Corner, 1976; González y Cristóbal, 2006). En un estudio anatómico en fruto de cacao Antillano realizado por Roth y Lindorf (1971) sobre el fruto y cubierta seminal, los autores no especifican los estados de desarrollo, tamaño de fruto o semilla, y sus descripciones son ilustradas con dibujos. En cambio, nuestras observaciones incluyen al saco embrionario, y los cambios estructurales de la semilla y embrión están referidos al tamaño de semilla y del fruto. La presente descripción estructural del origen subepidérmico de los sacos de mucílago coincide con el descrito por Roth y Lindorf (1971), pero nuestros resultados indican que estas estructuras inician su diferenciación en semillas de $1 \mathrm{~cm}$ (Etapa V; frutos 15.0 a $17.9 \mathrm{~cm}$ ), y la acumulación de mucílago en semillas de $1.5 \mathrm{~cm}$ (Etapa VI; frutos 18.0 a $20.9 \mathrm{~cm}$ ). 

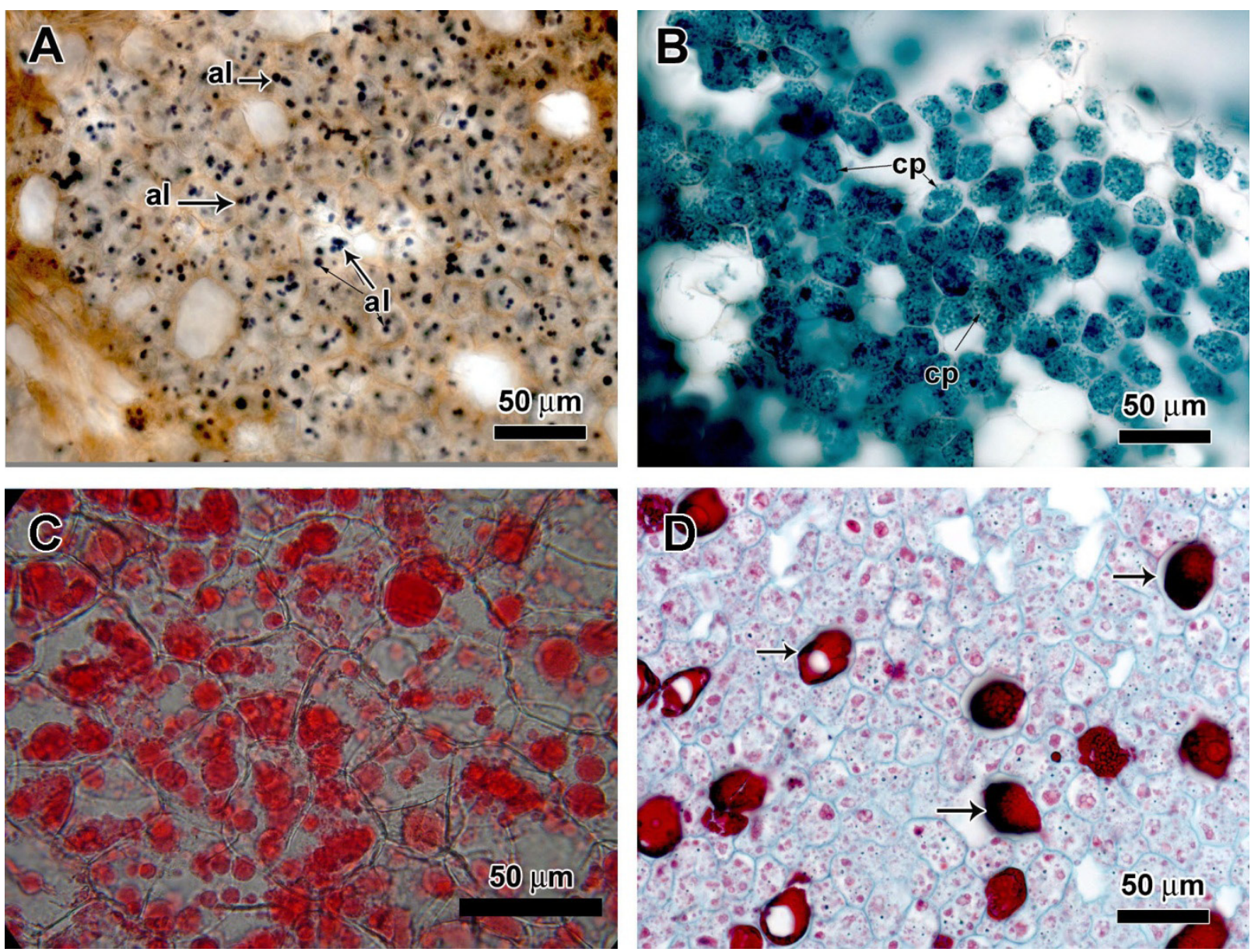

Figura 4. Histoquímica del embrión maduro de Theobroma cacao L. criollo. A) Parénquima cotiledonar con granos de almidón (al), en color negro. B) Cuerpos de proteína, en azul intenso (cp). C) Gotas de lípidos, en rojo. D) Flechas indican idioblastos con taninos condensados, en rojo.

Las semillas de los géneros Chiranthodendron, Commersonia, Hannafordia, Leptonychia, Rulingia, Seringia y Sterculia se describen como sésiles y ariladas; en contraste, $T$. cacao no desarrolla un arilo pero la pared de su fruto se mantiene unida la testa hasta la madurez, de manera que la pulpa del fruto está tan unida a la semilla que podría confundirse con un arilo. Con referencia al desarrollo del embrión, se ha reportado que el cigoto de T. cacao no se desarrolla inmediatamente después de la fecundación y que el embrión de Sterculia striata permanece en estado cordiforme hasta que la semilla alcanza aproximadamente $5 \mathrm{~mm}$ de diámetro (Sossou et al., 2002; González y Cristóbal, 2006).

De acuerdo con nuestras observaciones, el embrión del cacao Criollo se mantiene en estado globular $(0.28$ a 0.35 $\mathrm{mm}$ ) mientras que la cubierta seminal y endospermo continúan su crecimiento hasta $10 \mathrm{~mm}$ en las Etapa I, II y III (frutos 90 a $119 \mathrm{~mm}$ ). El temprano y abundante desarrollo de un endospermo celular en la región micropilar coincide con las descripciones de Dangou et al. (2002). La reanuda- ción del desarrollo del embrión ocurre en la Etapa IV, cuando inicia la formación de los cotiledones. Corner (1976) describió la presencia de pelos simples cilíndricos y obtusos en la epidermis cotiledonar de T. cacao, mientras que los cotiledones de 'Carmelo' fueron glabros, sin pelos. Martini et al. (2008) y Figueiredo (1986) reportaron la presencia de una membrana trasparente sobre el embrión maduro, pero según nuestras observaciones esta estructura corresponde a restos de endospermo.

Con referencia al tamaño del embrión, Angulo et al. (2001) reportaron variabilidad en las características físicas de las semillas de los cacaos Criollos, Forasteros y Trinitarios de la localidad de Cumboyo, Venezuela, entre los que destaca el tipo Criollo por tener semillas más pesadas, largas $(2.56 \pm 0.19 \mathrm{~cm})$, anchas $(1.42 \pm 0.08 \mathrm{~cm})$ y gruesas $(1.04 \pm$ $0.06 \mathrm{~cm}$ ). Aunque éste no fue el objetivo del trabajo, nuestros resultados muestran que la semilla del cacao criollo 'Carmelo' presenta dimensiones similares de largo (2.63 \pm $0.21 \mathrm{~cm})$, ancho $(1,43 \pm 0.07)$ y espesor $(1.00 \pm 0.06 \mathrm{~cm})$. En 
cuanto al color de los cotiledones, el cacao Criollo de Venezuela mostra alto porcentaje de color violeta claro (70 a 89 $\%$ ) seguido de tonalidades rosadas (10 a $20 \%$ ) y blancas (2 a $15 \%)$, según Angulo et al. (2001). El cacao criollo mexicano 'Carmelo' es predominantemente beige (\#F5F5DC) con 10 a $15 \%$ de tonalidades violeta claro. Se requieren más estudios para determinar la segregación del color en los genotipos mexicanos.

Las sustancias de reserva de los cotiledones de T. cacao son: lípidos $\left(492.4 \mathrm{mg} \mathrm{g}^{-1}\right)$, almidón $\left(340 \mathrm{mg} \mathrm{g}^{-1}\right)$, proteínas (143.5 $\left.\mathrm{mg} \mathrm{g}^{-1}\right)$ y polifenoles (79.9 $\mathrm{mg} \mathrm{g}^{-1}$ ) (Martini et al., 2008; Kalvatchev et al., 1998). Según las pruebas histoquímicas los almidones y proteínas se acumulan primero (Etapa VI, frutos 18:0 a $20.9 \mathrm{~cm}$ ). El almidón forma pequeños granos distribuidos uniformemente en el parénquima cotiledonar y las proteínas en cuerpos de proteína no cristalina, de acuerdo con Martini et al. (2008). En contraste con lo reportado por Martini et al. (2008), las células con taninos del criollo 'Carmelo' no se arreglan en hileras subepidérmicas anticlinales sino que los idioblastos están aislados y dispersos. Los lípidos son los últimos en acumularse, ya que los pequeños esferosomas aparecen cuando los cotiledones empiezan a plegarse (Etapa VII), y luego aumentan en número y tamaño para constituir el principal compuesto de reserva. Según Gilabert-Escrivá et al. (2002), el lípido más abundante en $T$. cacao es el ácido palmítico, seguido del oleico y esteárico.

Teichman y van Wyk (1994) revisaron el posible estado evolutivo y el significado funcional de la recalcitrancia y su relación con caracteres del óvulo y semilla en el marco del sistema moderno de clasificación de angiospermas. Especies con semillas recalcitrantes son usualmente maderables y la mayoría crece en ambientes húmedos tropicales o acuáticos, sus semillas están bien protegidas contra la desecación por una testa gruesa, y a veces con arilos. Nuestros resultados muestran que el óvulo de T. cacao criollo 'Carmelo' es bitégmico y crasinucelado con endospermo nuclear, caracteres significativamente asociados a la recalcitrancia en 45 familias de dicotiledóneas y considerados ancestrales (Teichman y van Wyk, 1994), Otras características de la semilla asociadas a la recalcitrancia son: semillas grandes, testas duras e impermeables, y presencia de arilos que reducen la deshidratación del embrión.

En el cacao criollo 'Carmelo' la semilla es grande pero la testa no es dura y no tiene arilo; en su lugar la testa contiene sacos de mucílago y la pulpa del fruto se adhiere persistentemente a la testa para cumplir una función de arilo. Duncan y Todd (1972) informaron de la presencia de células de mucílago en el eje embrionario y de antocianinas en el resto del parénquima cotiledonar del cacao Antillano. En los embriones del cacao criollo 'Carmelo' no se observan células de mucílago y tampoco células con antocianinas en los ejes embrionarios. Estas diferencias pueden deberse al genotipo y a que el embrión de 'Carmelo' es blanquecino, mientras que el Antillano es típicamente de color violáceo (Angulo et al., 2001).

\section{CONCLUSIONES}

La principal contribución del presente estudio es la descripción del saco embrionario y del desarrollo de la semilla en función de los tamaños de fruto del cacao criollo mexicano 'Carmelo', un genotipo aun no estudiado. El saco embrionario está formado por tres sinérgidas, dos antípodas, una ovocélula y una célula central binucleada. Este es el primer reporte en el género acerca del desarrollo tardío de haces postcalazales, carácter de valor taxonómico. El conocimiento de los cambios anatómicos de la semilla y su asociación con el tamaño del fruto permitirán hacer predicciones aproximadas de los estados de desarrollo del embrión y de la semilla, con base en las dimensiones de los frutos enteros en campo.

\section{BIBLIOGRAFÍA}

Angulo J, F L Graziani, B L Ortíz, P Parra (2001) Caracterización física de la semilla de cacao criollo, forastero amazónico y trinitario de la localidad de Cumboto, estado Aragua. Agron. Trop. 51:203-219.

Bewley J D (1995) Physiological aspects of desiccation tolerance. A retrospect. J. Plant Sci. 156:393-403.

Chacón P, R O Bustamente (2001) The effects of seed size and pericarp on seedling recruitment and biomasa in Cryptocarya alba (Lauraceae) under two contrasting moisture regimes. Vegetation 152:137-144.

Chopra R N, R C Sachar (1963) Endosperm. In: Recent Advances in the Embryology of Angiosperms, Chapter 6. P Maheshwari (ed). International Society of Plants Morphologists. University of Delhi, India. pp:135-169.

Corner E J (1976) The Seeds of Dicotyledons. Vol. 1. Cambridge University Press. 311 p.

Cuatrecasas J (1964) Cacao and its halleis. A taxonomic revision of the genus Theobroma. Contrib. US Nat. Herb. 35:379-61.

Dangou J S, V Hocher, N Ferrière, C Fulcheri, P Morard, L Alemanno (2002) Histological and biochemical characterization of Theobroma cacao L. endosperm during seed development. Seed Sci. Res. 12:91-100.

Duncan E J, A W Todd (1972) Structure of the mature embryo of Theobroma cacao L. Ann. Bot. 33:939-945.

Farnsworth E (2000) The ecology and physiology of viviparous and recalcitrant seeds. Ann. Ver. Ecol. Syst. 31: 107-138.

Figueiredo S F L (1986) Conservação da viabilidade da semente de cacau. II. Tipificação do fruto e descrição da sementes e da germinação. Rev. Theobroma 16:75-88.

Gentil D F O (2001) Consevação de sementes do cafeerio: resultados discordantes ou complementares? Bragantia 60:149-154.

Gilabert-Escrivá M V, L A G Gonçalves, L R S Silva, A Figueroa (2002) Fatty acid and triacylglicerol composition and thermal behavior of fats from seed of Brasilian Amazonian Theobroma species. J. Sci. Food Agric. 82:1425-1431.

González A M, C L Cristóbal (2006) Ontogenia del óvulo y semilla de Sterculia striata (Sterculiaceae). Bonplandia 15:63-77.

Guymer G P (1988) A taxomonic revision of Brachychiton (Sterculiaceae). Aust. Syst. Bot. 1: 199-323.

Hong T D, R H Ellis (1996) A Protocol to Determine Seed Storage Behaviour. Technical Bulletin No. 1. International Plant Genetic Resources Institute, Department of Agriculture, The University 
of Reading, UK. 62 p.

Jensen W A (1962) Botanical Histochemistry. Principles and Practice. Ed. W. H. Freeman. San Francisco, USA. 408 p.

Johri M B (1984) Embryology of Angiosperms. Ed. Springer-Verlag, Berlin-Heidelberg. 375 p.

Kalvatchev Z, D Garzaro, F Guerra Cedezo (1998) Theobroma cacao L: Un nuevo enfoque para la nutrición y la salud. Agroalimentaria 6:23-25.

Martini H M, G Lenci, C Figueira, De Q Tavares (2008) Localization of the cotyledon reserves of Theobroma grandiflorum (Hill. ex Spreng.) K. Schum., T. subincanum Mart., T. bicolor Bonpl. and their analogies with T. cacao L. Rev. Bras. Bot. 31:147-154.

Mendoza-López A, R A Gallardo-Méndez, C H Avendaño-Arrazate (2011) El mundo del cacao (Theobroma cacao L) kawa (Maya) cacahuatl (Náhuatl). Agroproductividad 4:20-26.

Moreno F, G Plaza, S Magnitskiy (2006) Efecto de la testa sobre la germinación en la semilla de caucho (Hevea brasilensis Muell.) Agron. Colomb. 25:290-295.

Pammenter N W, P Berjak, J M Farrant, M T Smith, Ross G (1994) Why do stored hydrated recalcitrant seed die? Seed Sci. Res. 4:187191.

Rangel F M A, L Córdova-Tellez L, A Delgado-Alvarado, H A Zavaleta-Mancera, A Villegas-Monter (2011) Tolerancia a la desecación en semillas de tres orígenes genéticos de cacao (Theobroma cacao L.). Rev. Fitotec. Mex. 34:175-182.
Rangel-Fajardo M A, A Delgado-Alvarado, L Córdova-Tellez, A Zavaleta-Mancera, A Villegas-Monter, A P López-Andrade , I Vidales-Fernández (2011) Accumulation of sugars in cocoa (Theobroma cacao L.) seeds of three genetics origins and its relationship to desiccation tolerance. Seed Sci. Tech. 39:1-11

Roberts E H (1973) Predicting the storage life of seeds. Seed Sci. Tech. 1:499-514.

Roth I, H Lindorf (1971) Desarrollo y anatomía del fruto de la semilla de Theobroma cacao L. Acta Bot. Ven. 6:261-195.

Ruzin E S (1999) Plant Microtechnique and Microscopy. Oxford University Press. New York. 386 p.

Sossou J D, V Hocher, N Ferrière, C Fulcheri, P Morard, L Alemanno (2002) Histological and biochemical characterization of Theobroma cacao L. endosperm during seed development. Seed Sci. Res. 12:91-100.

Teichman I, A E van Wyk (1994) Structural aspects and trends in the evolution of recalcitrant seeds in dicotyledons. Seed Sci. Res. 4:225-239.

Zavaleta-Mancera H A, E M Engleman (1991) Anatomía de la semilla de Casimiroa edulis (Rutaceae) "zapote blanco", durante su desarrollo. Bol. Soc. Bot. Méx. 51:67-81.

Zavaleta-Mancera H A, E M Engleman (1994) Anatomy of the ovule and seed of Manilkara zapota (L.) van Royen (Sapotaceae). Phytomorphology 44:169-175. 